ENCYCLOPEDDIE Encyclopédie berbère

BERBERE

$7 \mid 1989$

7 | Asarakae - Aurès

\title{
Assabet El Meddahia
}

N. Lambert

\section{OpenEdition}

Journals

Édition électronique

URL : http://journals.openedition.org/encyclopedieberbere/1198

DOI : 10.4000/encyclopedieberbere.1198

ISSN : 2262-7197

\section{Éditeur}

Peeters Publishers

\section{Édition imprimée}

Date de publication : 1 janvier 1989

Pagination : 983-986

ISBN : 2-85744-443-5

ISSN : $1015-7344$

\section{Référence électronique}

N. Lambert, « Assabet El Meddahia », Encyclopédie berbère [En ligne], 7| 1989, document A299, mis en ligne le 01 décembre 2012, consulté le 13 octobre 2020. URL : http://journals.openedition.org/ encyclopedieberbere/1198; DOI : https://doi.org/10.4000/encyclopedieberbere.1198

Ce document a été généré automatiquement le 13 octobre 2020

(C) Tous droits réservés 


\section{Assabet El Meddahia}

\section{N. Lambert}

1 Entre un relief en "cuesta " de grès infracambriens, l'Assabet-el-Meddahia, et la bordure nord de l'erg du Makteir, à $110 \mathrm{~km}$ à l'est de la Kédia Idjil s'étend une dépression dont les rives abondent en vestiges préhistoriques et préislamiques. Elle se situe entre $22^{\circ} 06^{\prime}$ et $22^{\circ} 09^{\prime}$ Nord et entre $11^{\circ} 48^{\prime}$ et $11^{\circ} 51^{\prime}$ Ouest environ.

2 Des emplacements de campements néolithiques occupent d'anciennes collines à la lisières des sables du Makteir. Plusieurs foyers domestiques ont fourni des restes de grande faune (équidés et bovidés). Deux datations radiométriques ont été obtenues ( $2500 \pm 100$ et $2590 \pm 100$ B.P.).

3 De nombreuses meules dormantes, plates ou creuses mais toujours bien façonnées, en grès ou en quartzite micassé, avec leurs molettes, des haches épaisses en roche verte polie, des hachettes et des herminettes, des ciseaux et des repoussoirs sur plaquettes de phtanite à tranchant poli sont associés à de l'outillage lithique taillé où figurent de nombreuses armatures de flèches pédonculées, des grattoirs, des perçoirs et des pièces en $\mathrm{T}$.

4 Le façonnage de l'œuf d'autruche n'apparaît que dans les perles discoïdales et des fragments polygonaux découpés.

Bracelets en roches diverses polies, perles et pendeloques en test d'œuf d'autruche, perles en amazonite, en coquille et cristaux de quartz hyalin représentent la parure.

6 Les poteries, généralement d'assez grande taille, souvent entières, sont à panse globulaire tantôt largement ouvertes tantôt à col resserré, rarement à goulot. Le décor au peigne couvre parfois la totalité du vase ou forme un bandeau sous le bord.

7 Une modeste série d'objets en cuivre, recueillis entre le fond lacustre et le site de Dechra 1 , sont à mettre en rapport avec les traces d'un petit atelier métallurgique découvert sur cet habitat. Des scories, quelques résidus de fonte, des chutes de minces tôles de cuivre signalent l'emplacement où a dû travailler un forgeron. Les analyses spectographiques faites sur ces fragments et sur une alène montrent une composition très proche de celles observées dans les cuivres d'Akjoujt*. 
8 Sur la rive nord de la dépression, l'Oued Rkeiz coule entre deux petites falaises qui ont servi de support aux artistes néolithiques. On peut y voir des peintures à l'ocre jaune qui se détachent sur la patine brun-noir des grès. Les silhouettes de trois éléphants surmontent quatre antilopes.

9 Ce site offre également des gravures piquetées : girafes, signes anthropomorphes et surtout bovidés. Une belle composition représentant une douzaine de bœufs, de vaches et de veaux, marchant de gauche à droite, couvre une grande dalle inclinée de 3,25 m de long.

10 Le plafond d'un petit abri au pied de la falaise présente quelques caractères tifinagh peints à l'ocre jaune et rouge.

11 Les reliefs rocheux qui limitent la dépression vers le Nord ont servi de nécropole. De nombreux tumulus sont dispersés de part et d'autre de l'Oued Rkeiz. Il faut signaler également deux tumulus à chapelle à Aouchich, à une vingtaine de kilomètres à l'ouest.

En haut : Éléphants et antilopes peints d'Assabet (photo N. Lambert). Ci-dessus : Gravures de bovidés (photo $N$. Lambert).

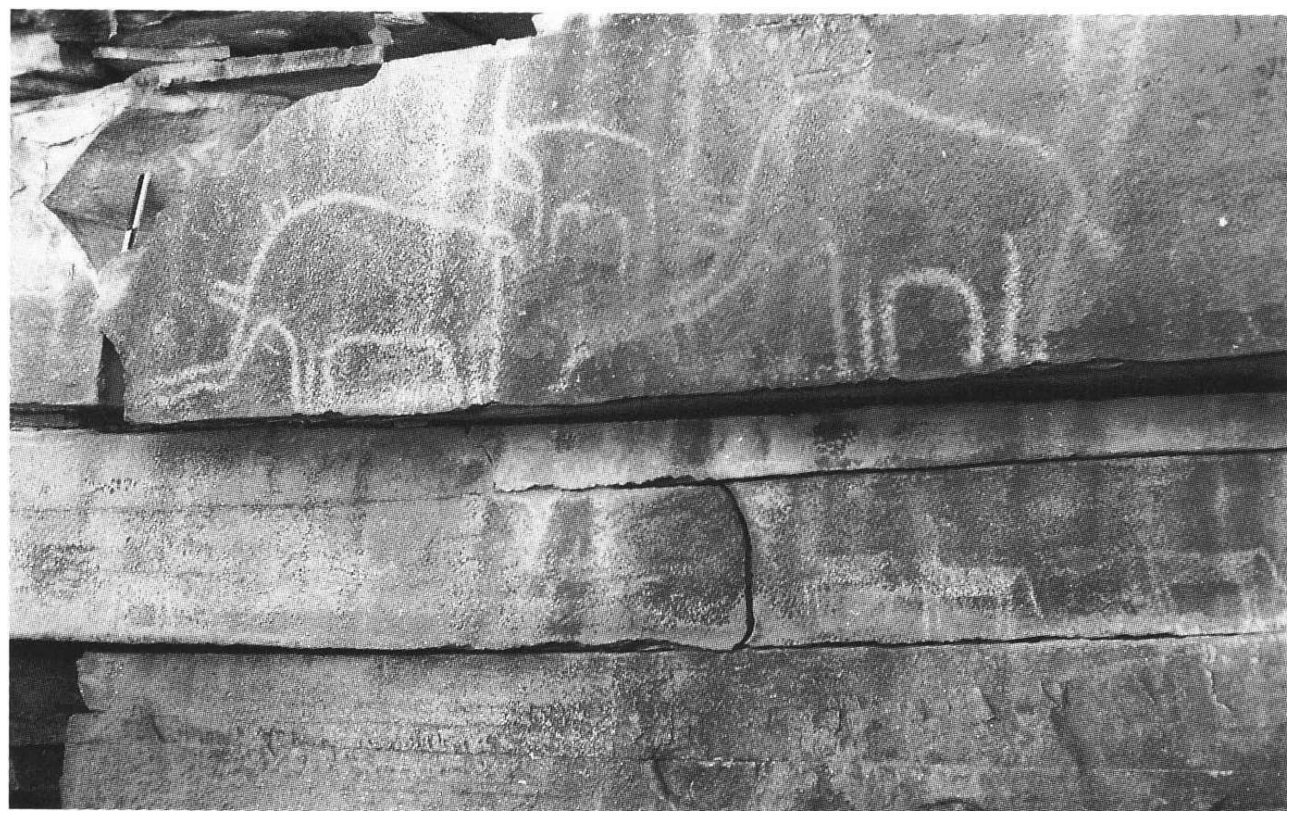




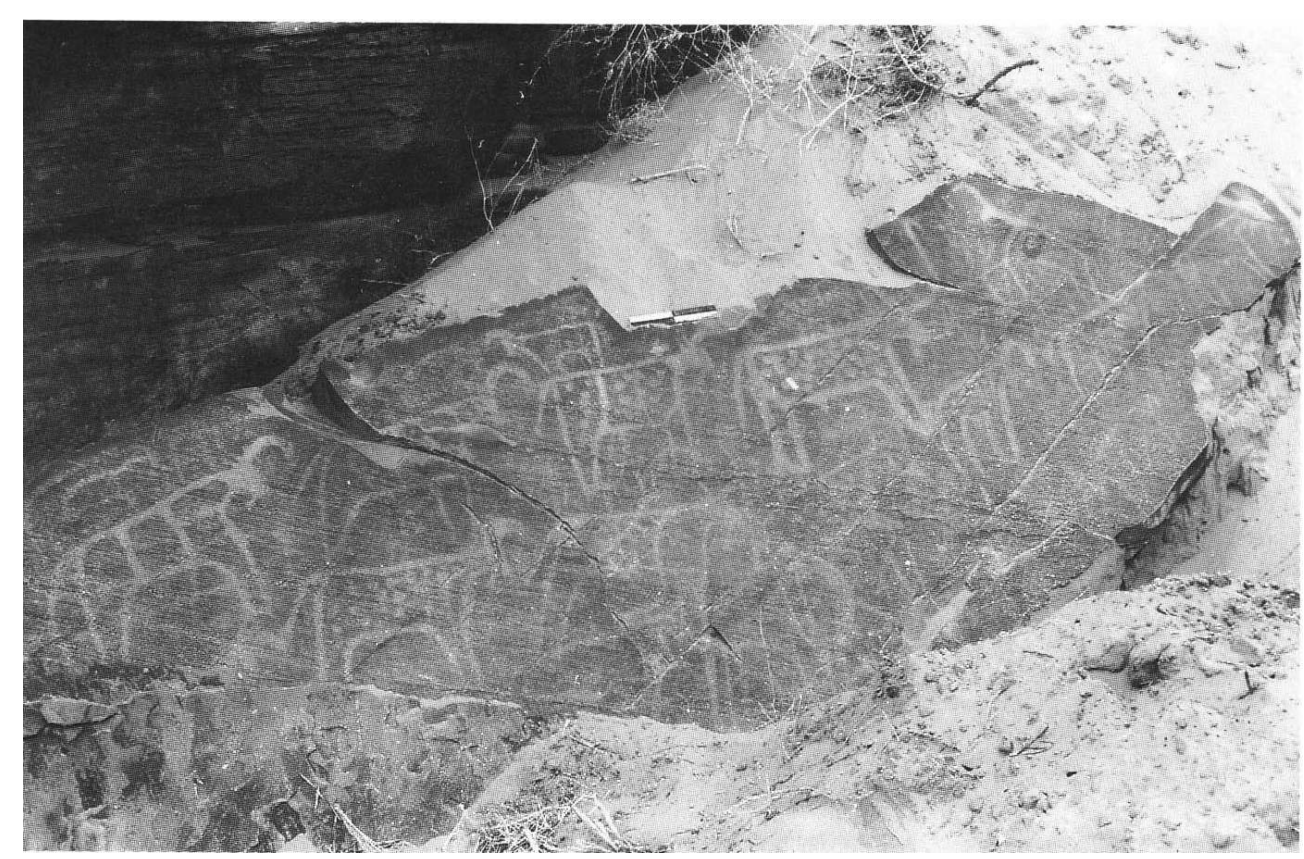

12 Mais les monuments qui attirent l'attention sont surtout ceux qui se dressent au débouché de l'oued Rkeiz dans le fond lacustre. Ils sont au nombre de trois, espacés de quelques centaines de mètres. De faible hauteur mais de grandes dimensions ils se composent :

a) d'une grande aire circulaire (de $10 \mathrm{~m}$ de diamètre environ) légèrement surélevée par rapport au sol environnant, cernée de blocs de grés profondément enfoncés dans le sol et plantée de petites pierres levées (entre 110 et 30 pierres) sur toute sa surface. Vers l'est un petit espace vide limité lui aussi par un alignement de pierres, ouvre vers l'extérieur, empiète sur l'aire circulaire et interrompt l'enceinte. Deux ou quatre pierres dressées marquent, à l'extérieur, l'entrée du monument vers l'est.

b) de plusieurs petites aires circulaires (3 à 6, de 2 à $5 \mathrm{~m}$ de diamètre) limitées par de grosses pierres. Ces aires sont plus ou moins tangentes les unes aux autres et disposées en arc de cercle face à l'entrée de l'aire principale. Leur surface est couverte de cailloutis ou de plaquettes de pierre.

13 La distance entre le grand cercle et ses satellites est variable : ceux-ci sont presque juxtaposés à l'aire principale dans le monument est mais une quinzaine de mètres les en séparent dans le monument ouest 1.

14 A l'intérieur et aux alentours de ces monuments on a recueilli quelques perles en test d'œuf d'autruche et en amazonite ainsi que des esquilles osseuses portant des traces d'utilisation et, parmi celles-ci un poinçon. 
Assabet el Médina, monument circulaire avec pierres dressées et trois aires satellites au second plan (photo N. Lambert).

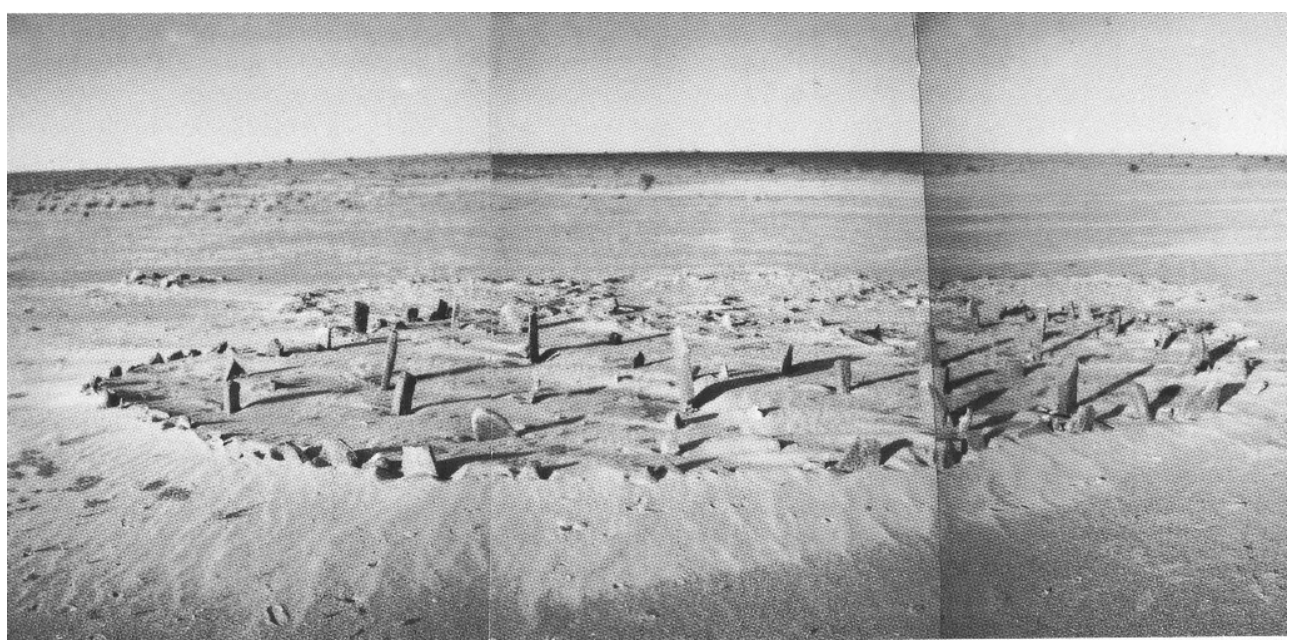

Cet ensemble de l'Assabet-el-Meddahia, qui se trouve entre les sites néolithiques du nord de l'Adrar (Oumm Arouaba) et ceux de la région de Zouerate (Azreg) fournit les premières données sur l'occupation humaine durant les dernières phases des temps préhistoriques, sur les activités artistiques (rupestres) et artisanales (métallurgie) dans cette partie nord de la Mauritanie. Il confirme enfin la réalité des échanges de cette région avec la côte atlantique $(600 \mathrm{~km})$ d'où viennent des coquilles marines façonnées ou non, avec l'Adrar $(200 \mathrm{~km})$ d'où viennent les plaquettes de phtanite et avec la région d'Akjoujt $(400 \mathrm{~km})$ d'où viennent les roches vertes et le cuivre.

\section{BIBLIOGRAPHIE}

LERICHE A., « Terminologie géographique maure », Études mauritaniennes n 6, 1955, Centre I.F.A.N. Mauritanie, Saint-Louis.

MILBURN M., Monuments lithiques et funéraires anciens du Sahara (premiers éléments d'une enquête), Thèse d'université, Paris I, 1978.

MONOD Th., «Sur quelques monuments lithiques du Sahara occidental Homenaje a Juan Martinez Santa-Olalla, III », Actas y Memorias de la Societad Española de Antropología, Etnografía y Prehistoria, XXIII, Cuaderno 1-4, Instituto Bernardino de Sahabun, Madrid 1948.

RENOUX Lt A., « Vestiges humains dans la région d'Aouriche (Mauritanie) », Bull. Com. Et. Hist, et Sc. A.O.F., 1937, p. 147-152.

VERNET R., La préhistoire de la Mauritanie. Etat de la question, Thèse Univ. de Paris I, 1983, 3 vol. 792 p. ronéo. 
INDEX

Mots-clés : Mauritanie 